\title{
Pengaruh Penggunaan Infra Red di Posyandu Lansia Desa Lama
}

\section{Influence of Infrared Use in Posyandu Lansia Desa Lama}

\author{
Sulaiman \& Anggriani
}

Program Studi Fisioterapi Stikes Siti Hajar

Diterima: Juli 2019; Disetujui: Agustus 2019 ; Dipublish: September 2019

\begin{abstract}
Abstrak
Posyandu lansia adalah salah satu bentuk upaya pelayanan kesehatan daya dari masyarakat Desa Lama Kecamatan Pancur Batu dalam memberikan pelayanan dasar khususnya pada lanjut usiaagar dapat terpenuhi haknya dalam pelayanan kesehatan. Penduduk usia 60 tahun ke atas sebanyak 120 jiwa, rata-rata lansia mengalami gangguan fisik dan perlu penanganan yang lebih maksimal. Tujuan pengabdian ini adalah memberikan sosialisasi penggunaan sinar infra red kepada kader, keluarga lansia dan lansia. Dalam pengabdian ini metode dilakukan adalah dengan melakukan penyuluhan, pelatihan penggunaan infra red kepada lanjut usia, kader dan keluarga yang mengikuti pengabdian masyarakat. Tingkat kesehatan lanjut usia meningkat, kader dan keluarga lanjut usia mengerti cara menggunakan infra red. Pemberian sinar infra red sangat memberikan dampak yang sangat signifikan dalam peningkatan derajat kesehatan lanjut usia di Desa Lama Kecamatan Pancur Batu.
\end{abstract}

Kata Kunci: Posyandu Lansia, Infra Red

\section{Abstract}

The elderly Posyandu is a form of health service from the community of Lama Village, Pancur Batu District, in providing basic services specifically for the elderly, their rights in health services can be fulfilled. Population aged 60 years and over as many as 120 people, the average elderly are looking for physical care and better. The purpose of this service is to provide information on the use of infrared light for cadres, elderly families and the elderly. In this service the method used is to do counseling, training in the use of infrared for the age, cadres and families who take part in community service. The health level of the elderly is increasing, cadres and elderly families understand how to use infra red. Provision of infrared light has a very significant impact in improving health status in Lama Village, Pancur Batu District.

Keywords: Elderly Posyandu, Infra Red

How to cite : Sulaiman. \& Anggriani. (2019). Pengaruh Penggunaan Infra Red di Posyandu Lansia Desa Lama. Pelita Masyarakat : Jurnal Pengabdian Masyarakat 1(1) :46-54

\section{PENDAHULUAN}

Desa Lama merupakan salah satu desa yang ada di Kecamatan Pancur Batu Kabupaten Deli Sedang Provinsi Sumatera Utara. Penduduk usia 60 tahun keatas ratarata mengalami gangguan fisik yang selama ini masih belum tertangani dengan baik. Hal ini dapat menjadi permasalahan nasional jika penanganan kesehatan pada lansia tidak ditanagnai dengan baik. Pihak-pihak yang selama ini memberikan pelayanan dasar kesehatan adalah posyandu lansia yang ada di desa tersebut, kader posyandu dalam 
memberikan pelayanan pada lansia selama ini tidak memberikan solusi tentang kesehatan lansia, sehingga keluarga enggan mengantarkan lansia ke posyandu. Oleh sebab itu perlu diberikan inovasi dalam kegiatan posyandu dengan pemberian sinar infra red pada lansia.

Infra Red (IR) merupakan salah satu modalitas bagi seorang fisioterapis dalam menangani pasien fisioterapi yang mengalami berbagai gangguan fisik. Gangguan fisik yang dialami oleh lanjut usia (lansia) sangatlah komplek, untuk itu diperlukan penanganan yang sangat serius. Pemberian sinar infra red (IR) diberikan kepada lansia dengan tujuan untuk menstimulasi reseptor panas yang berfungsi sebagai pengurang rasa nyeri, penguatan otot yang berperan penting dalam menjaga kesehatan lansia. Lansia sering terkena penyakit Osteoarthritis, obesitas, stoke, keseimbangan sehingga sangat mengganggu aktifitas fisik maupun lansia dan keluarga. Adanya permasalahan yang muncul baik pada tingkat impainment, functional limitation, dan disability sehingga diperlukan penanganan fisioterapis secara efektif dalam hal ini adalah pemberian terapi dengan menggunakan Inf sinar infra red dan terapi latihan. Infra red. Untuk gangguan fisik berupa OA, stroke, keseimbangan tubuh dan lainnya diberikan penyinaran dengan dosis 3 kali seminggu dalam waktu 15, permasalahan yang didapatkan pasien lansia diatas 60 tahun sering terdiagnosis osteoarthritis. Setelah dilakukan terapi sebanyak 6 kali dengan modalitas Infra Red, terjadi penurunan nyeri, peningkatan kekuatan otot, dan peningkatan kekuatan fungsional. Dalam proses pemulihan menujukan normal pada kasus OA membutuhkan waktu yang lama (Cahyo, 2017).

Seiring dengan meningkatnya kesehatan lansia di Indonesia, proyeksi penduduk 2010-2035, Indonesia akan memasuki periode lansia (ageing), dimana 10\% penduduk akan berusia 60 tahun ke atas. Sejak tahun 2004 - 2015 memperlihatkan adanya peningkatan Usia Harapan Hidup di Indonesia dari 68,6 tahun menjadi 70,8 tahun dan proyeksi tahun 2030-2035 mencapai 72,2 tahun (Kemenkes RI, 2016)

Meningkatnya usia harapan hidup sebagai bukti gambaran keberhasilan kesehatan di Indonesia, namun disisi lain meningkatkanya usia harapan hidup menjadi beban pemerintah. Diperkirakan tahun 2017 jumlah penduduk lansia usia diatas 60 tahun sebanayak 23.658.21 jiwa (Kemenkes RI, 2017) 


\section{ANALISIS SITUASIONAL}

Desa Lama merupakan salah satu desa dari 25 desa yang ada di Kecamatan Pancur Batu . Desa Lama dipimpin oleh seorang Kepala Desa bernama Nizar Laksamana Tarigan. Luas Desa Lama adalah 116 hektar. Rata-rata penduduk suku Karo dan sebagaian besar penduduk pekerjaannya adalah petani. Jumlah penduduk Desa Lama sebanyak 5.725 jiwa dan 120 jiwa sudah memasuki lanjut usia yaitu daiatas 60 tahun (Profil Desa Lama. 2018). Keberadaan Desa Lama ini tidak jauh dari ibukota Kecamatan Pancur Batu, dibandingkan dengan desa-desa lainnya yang ada di Kecamatan pancur Batu. Hal ini memudahkan akses bagi kepala desa dan masyarakat Desa Lama untuk melengkapi surat-surat adminsitrasi kependudukan seperti kartu keluarga, KTP dan lain sebagainya.

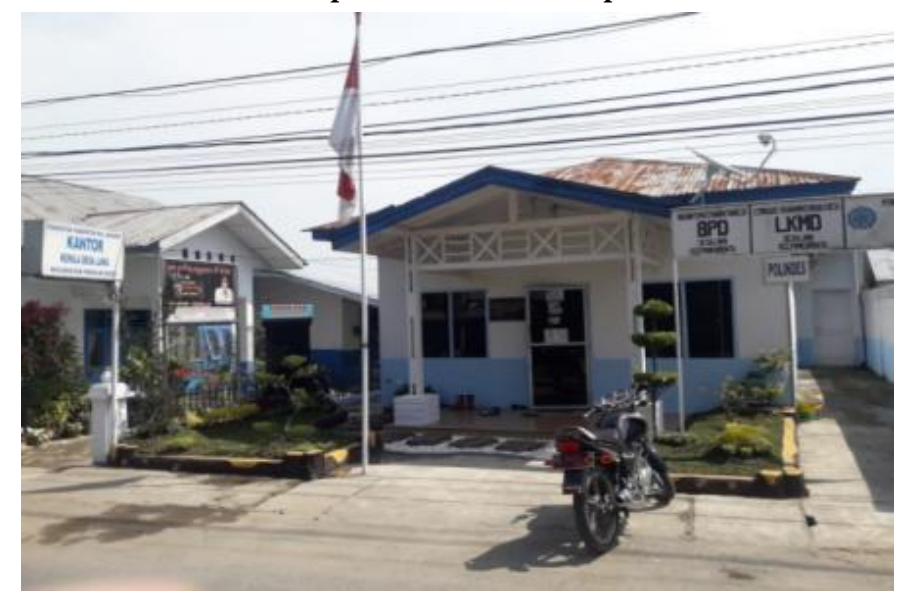

Gambar 1. Kantor Kepala Desa Lama

Dalam setiap kegiatan posyandu, sebagian besar lansia tidak memeriksa kesehatannya di posyandu dengan berbagai alasan. Hal ini merupakan yang menjadi permasalahan penting bagi lansia yang ada di Desa Lama sehingga kesehatan para lansia menurun. Posyandu lansia merupakan salah satu upaya kesehatan dasar bersumber dari masyarakat yang melibatkan partisipasi masyarakat dalam pelaksanaannya. Posyandu juga sebagai perpanjangan tangan Puskesmas yang memberikan pelayanan dan pemantauan kesehatan yang dilaksanakan secara terpadu. 
Kegiatan-kegiatannya dilaksanakan oleh kader kesehatan yang telah mendapatkan pendidikan dan pelatihan dari Puskesmas mengenai Pelayanan kesehatan dasar (Penelitian \& Pengembangan, 2010)

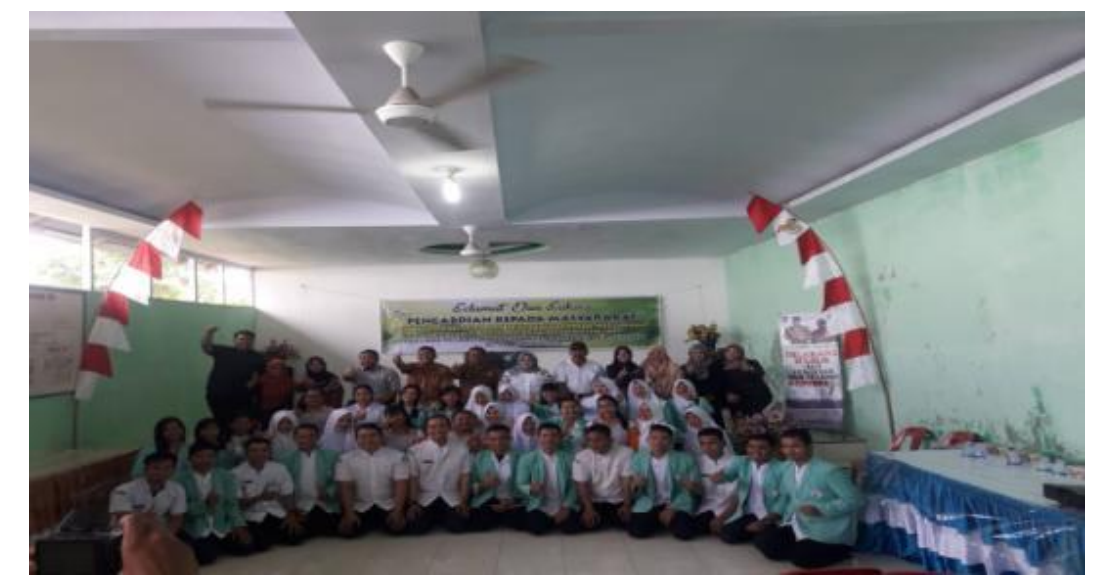

Gambar 2. Balai Desa Lama (tempat pelaksanaan Posyandu)

Pengabdian Kepada Masyarakat yang dilakukan oleh Sulaiman dkk terhadap kader posyandu lansia dalam pelatihan penggunaan infra red menunjukkan bahwa terjadi peningkatan kunjungan lansia ke posyandu lansia sebesar 30\% Kader posyandu dan keluarga lansia turut berpartisipasi aktif dalam membantu peningkatan kunjungan lansia ke posyandu lansia (Sulaiman, Sutandra, \& Vera, 2018). Begitu juga pengabdian yang dilakukan di Desa Suka Raya Kecamatan Pancur Batu Kabupaten Deli Serdang Sumatera Utara. Banyak sekali lansia mengalami gangguan musculokeletal yang di alami oleh lansia seperti gangguan keseimbangan postur tubuh yang bururk terhadap lansia. Hal ini terjadi salah satu penyebabnya karena lansia malas datang ke posyandu setiap bulannya untuk mengecek kesehatan lansia (Sulaiman \& Anggriani, 2018).

Selain itu lansia yang malas memeriksa kesehatannya bisa terkena Diabetes Melitus (DM) dimana merupakan keadaan yang seringkali dikaitkan dengan meningkatnya risiko kesakitan dan kematian. Lanjut usia (lansia) yang menderita DM seringkali juga mengalami penyakit lainnya, ketidakmampuan fisik, gangguan psikososial dan fungsi kognisi, serta meningkatnya pelayanan kedokteran. Padaakhirnya, komplikasi yang terjadi akan mempengaruhi kualitas hidup lansia. Lansia pria mempunyai rata-rata skor 
lebih tinggi pada domain kesehatan fisik dan hubungan sosial dibandingkan dengan lansia wanita. (Khairani, 2007).

\section{Permasalahan.}

Dalam analisis situasi didapatkan permasalahan yang dihadapi oleh lansia di Desa Lama Kecamatan Pancur Batu adalah sebagai berikut.

1. Lanjut usia rata-rata mengalami gangguan musculoskeletal yaitu Osteoarthritis, lowbackpain, stroke dan keseimbangan postur tubuh.

2. Posyandu yang dilaksanakan khusus lansia sangat sedikti diminati.

3. Lokasi yang jauh dari rumah lansia dengan kegaiatan psoyandu.

4. Transportasi yang tidak ada ke tempat posyandu.

Hal ini yang melatarbelakangi kegiaan pengabdian masyarakat dilakukan di Desa Lama Kecamatan Pancur Batu Kabupaten Deli Serdang dilakukan.

\section{Permasalahan Prioritas.}

Melihat kompleksnya permasalahan yang di hadapi oleh lansia di Desa Lama Kecamatan Pancur Batu, tim pengabdian melakukan permasalahan yang prioritas terlebih dahulu, yaitu memberikan pemberian sinar infra red kepada lansia yang mengalami gangguan fisik seperti osteoarthritis, lowbackpain, stroke, keseimbangan postur tubuh dan gangguan fisik lainnya.

\section{Solusi}

Melihat permasalahan prioritas yang akan dilakukan dalam pengabdian ini, tim pengabdian melakukan langkah-langkah yang tepat dan solutif untuk dapat menyelesaikan permasalahan prioritas yang dihadapi oleh para lansia sebagai berikut :

1. Memberikan Penyuluhan kepada lansia dan keluarga lansia

2. Memberikan pelatihan dasar penggunaan infra red kepada kader dan keluarga lansia

3. Memberian penyinaran sinar infra red keada lansia

\section{Target}


Target dalam kegiatan pengabdian ini secara umum adalah terjadi peningkatan kesehatan pada lansia dan perubahan perilaku lansia yang semula malas datang ke posyandu menjadi rajin hadir memeriksakan kesehatanya ke posyandu.

\section{METODE PELAKSANAAN}

Pengabdian masyarakat yang dilakukan ini di Desa Lama Kecamatan pancur Batu Kabupaten Deli Serang Sumatera Utara, kegiatan ini dilakukan selama dua hari dengan populasi semua lansia yang ada di Desa tersebut. Sampelnya yang diambil adalah yang memenuhi kriteria inklusi yaitu lansia yang datang mengikuti kegiatan pengabdian selama dua hari sebanyak 40 oarng. Dan apabila sampel melebihi, maka akan dilakukan dengan teknik random samping. Dalam mengkukur hasil dari pengabdian ini dengan menggunakan instrument berupa kuisioner dan wawancara diakhir kegiatan. agar target yang diharapkan dan dengan melihat skala prioritas solusi yang telah ditetapkan, maka metode pelaksanaannya dengan memberikan penyuluhan dan pemberian sinar infra red

\section{HASIL DAN PEMBAHASAN}

\section{Penyuluhan}

Kegiatan penyuluhan dilakukan di Balai Desa Lama dihadiri oleh lansia dan keluarga lansia. Dalam penyuluhan ini tim memberikan ceramah bagaimana agar kesehatan lansia tetap terjaga sampai akhir hayat. Memberikan semangat hidup kepada lansia. Lansia merasa dirinya tidak berguna dihadapan para keluarga, masyarakat, merasa menjadi beban, sehingga dapat mengakibatkan menurunnya kesehatan lansia.

Dalam penyuluhan ini tim juga memberikan penerangan teknik dan manfaat infra red bagi lansia dan keluarga. Selain harga infra red yang realtif murah, manfaat infra red juga sangat banyak. Keluarga lansia nantinya dapat memberikan kepada lansia karena telah mengikuti penyuluhan yang diberikan oleh tim pengabdiani. Ceramah dan pealtihan dilakukan mulai pukul 09.00 - dengan 14.00 WIB. Hal ini dilakukan penyuluhan terlebih dahulu agar kegiatan dihari kedua para lansia dan keluarga telah memahami manfaat pemberian sinar infra red. Selain itu penyuluhan ini juga memberikan bantuan kepada kader berupa alat infra red kepada kader. Tujuannya agar pada saat kegiatan posyandu setiap bulannya infra red dapat dipergunakan dengan baik 
oleh para kader dan keluarga lansia. Penyuluhan ini juga memberikan sesi tanya jawab kepada seluruh peserta. Kegiatan penyuluhan ini dapat dilihat pada gambar 3 berikut ini.

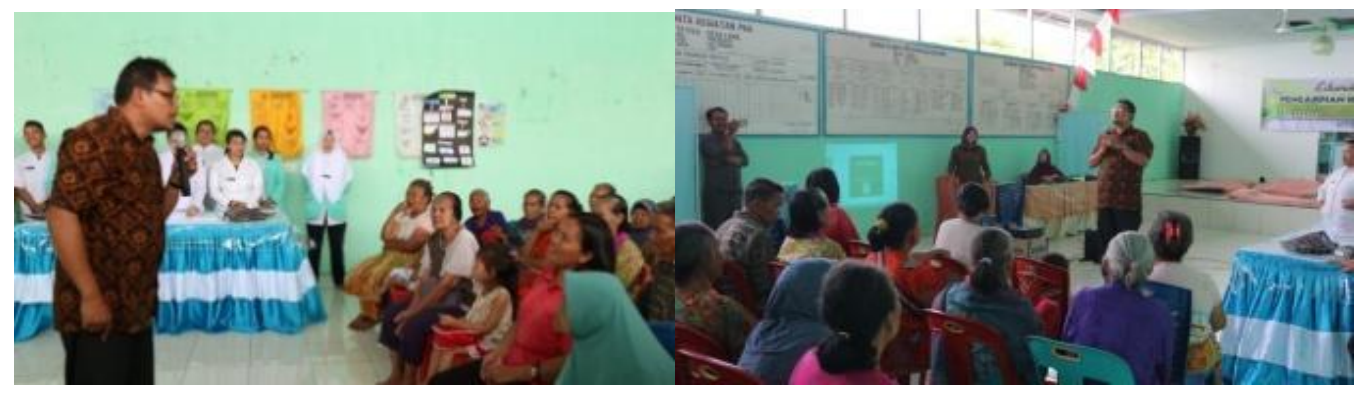

Gambar 3. Penyuluhan dan tanya jawab

\section{Pemberian Sinar Infra Red}

Pelaksanaan kegiatan pengabdian pada hari kedua adalah penanganan langsung dengan cara memberikan sinar infra red kepada lansia. Lansia sangat antusias untuk mendapatkan penanganan oleh tim pengabdian. Pemberian sinar infra red ini dilakukan selama 15 menit pertama kemudian dilakukan lagi 15 menit berikutnya. Dengan diberikan infra red ini sirkulasi darah dalam tubuh lansia akan lancar. Sehingga gangguan-gangguan kesehatan yang dihadapai lansia dapat berkurang.

Kegiatan pemberian sinar infra red ini dapat dilihat pada gambar 4 berikut ini.
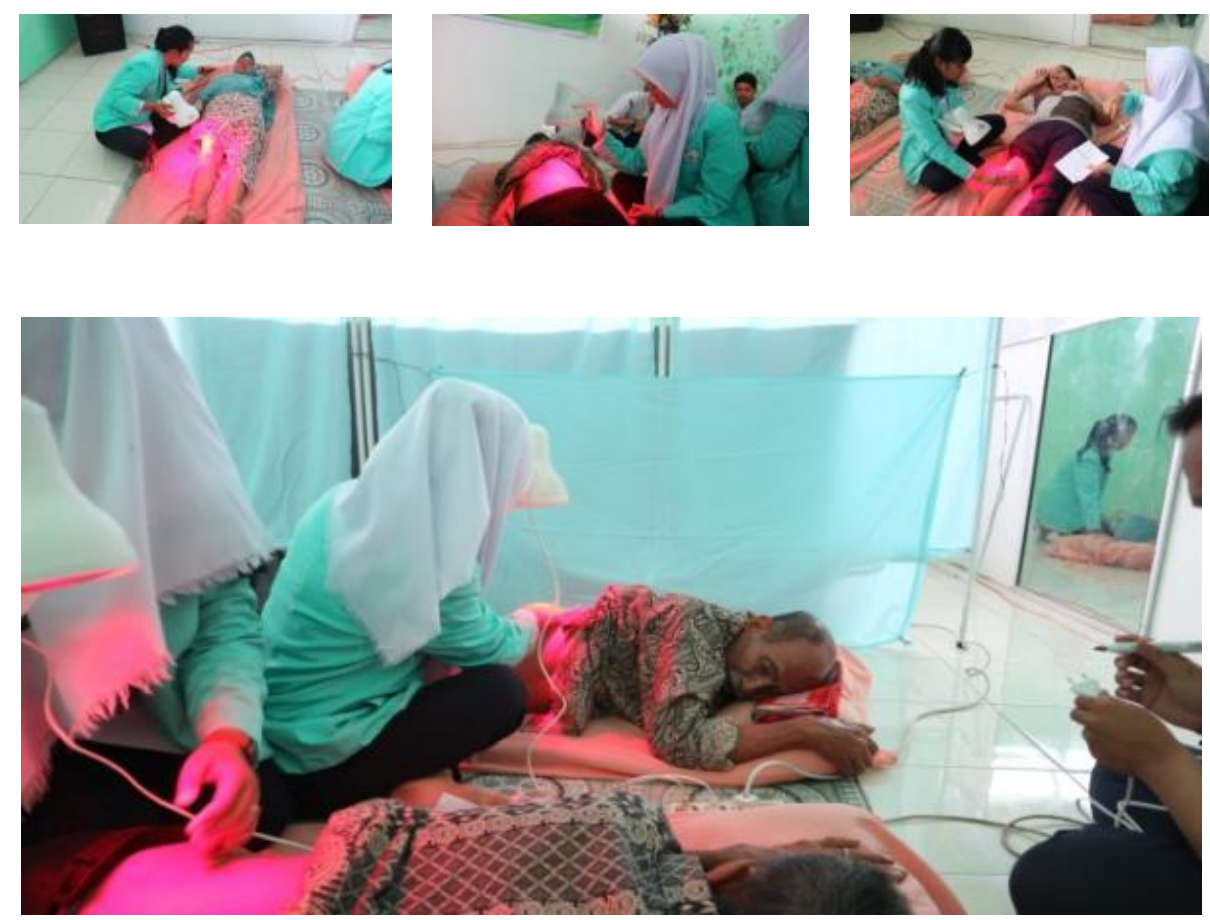
Hasil dari kegiatan penyuluhan yang dilakukan tim pengabdian menyatakan bahwa $80 \%$ lansia menyatakan puas dan 20\% menyatakan tidak puas, hal ini seperti terlihat pada Tabel 1 berikut ini.

Tabel 1. Tanggapan responden terhadap penyuluhan

\begin{tabular}{|l|c|c|}
\hline \multicolumn{1}{|c|}{ Katagori } & $\begin{array}{c}\text { Frekuensi } \\
\text { (Jumlah) }\end{array}$ & $\begin{array}{c}\text { Persentasi } \\
(\%)\end{array}$ \\
\hline Puas & 32 & 80 \\
\hline Tidak Puas & 8 & 20 \\
\hline Jumlah & 40 & 100 \\
\hline
\end{tabular}

Melihat tabel 1 diatas, rata rata responden sangat puas sebanyak 80\% dikarenakan tim dalam melakukan penyuluhan bersungguh-sungguh dengan pendekatan sosial yang lebih diutamakan. Sedangakan yang tidak puas sebanyak 20\% disebabkan responden tidak mendengar dengan jelas pada saat diberika penyuluhan dan duduk dibelakang.

Untuk pemberian sinar infra red rata-rata responden menyatakan sangat puas sebanyak 90\%, hal ini dikarenakan responden langsung merasakan manfaat yang didapat dari sinar infra red, alasana berikutnya selama ini diposyandu lansia tidak diberikan sinar infra red oleh kader dan tenaga kesehatan. Kemudian 10\% responden sebanyak $10 \%$ menyatakan tidak puas. Hal ini disebabkan responden tidak mendapatkan manfaat langsung dari pemberian sinar infra red. Hal ini dapat dilihat pada tabel 2 berikut ini :

Tabel 2. Peryataan Responden terhadap pemberian sinar infra red

\begin{tabular}{|c|c|c|}
\hline Katagori & $\begin{array}{c}\text { Frekuensi } \\
\text { (Jumlah) }\end{array}$ & $\begin{array}{c}\text { Persentasi } \\
(\%)\end{array}$ \\
\hline Puas & 36 & 90 \\
\hline Tidak Puas & 4 & 10 \\
\hline Jumlah & 40 & 100 \\
\hline
\end{tabular}


Hasil pengabdian ini sesuai yang dilaksanakan di Desa Suka Raya Kecamatan Pancur Batu kabupaten Deli Serdang bahwa ada pengaruh peningkatan pengetahuan kader, lansia dan keluarga tentang kesehatan setelah diberikan penyuluhan dan pemberian sinar infra red (Sulaiman et al., 2018). Begitu juga penelitian yang dilakukan di Desa Suka Raya menyatakan bahwa pengetahuan lansia, sikap lansia, dukungan keluarga, dukungan kader dan keterjangkauan responden berhubungan dengan pemanfaatan Posyandu lansia, sehingga variabel tersebut sangat mempengaruhi derajat kesehatan lansia (Sulaiman, 2016)

\section{SIMPULAN}

Dari hasil dari tim pengabdian yang dilakukan selama 2 hari, tim pengabdian dapat menyimpulan sebagai berikut.

1. Pemberian sinar infra red dapat diberikan dalam kegiatan posyandu yang dilakukan setiap bulannya karena lansia menjadi rajin unutk datang keposyandu.

2. Target pengabdian tercapai sesuai harapan yang telah ditetapkan diawal pengabdian.

3. Perlu dilakukan pengabdian setiap tahunnya di Desa lama Kecamatan Batu, dengan metode yang lainnya dan durasi waktuyang lebih lama lagi.

\section{DAFTAR PUSTAKA}

Cahyo, Is. (2017). Penatalaksanaan Fisioterapi Pada Kasus Osteoarthritis Genu Sinistra Di RSU Aisyiyah Ponorogo. Libraryums, 1(1), 1-9. Retrieved from http://eprints.ums.ac.id/55753/11/NASKAH PUBLIKASI-Ismail-libraryums.pdf

Kemenkes RI. (2016). Situasi lanjut usia (lansia), 1-8. Retrieved from http://www.pusdatin.kemkes.go.id/resources/download/pusdatin/profil-kesehatanindonesia/Data-dan-Informasi_Profil-Kesehatan-Indonesia-2017.pdf

Kemenkes RI. (2017). Profil Kesehatan Indonesia 2017. (M. K. drg.Rudy Kurniawan, Ed.). Jakarta: Kemenkes RI.

Khairani, R. (2007). Prevalensi diabetes melitus dan hubungannya dengan kualitas hidup lanjut usia di $\begin{array}{llll}\text { masyarakat. } & \text { Universa } & \text { Medicina, } & \text { Retrieved }\end{array}$ https://www.univmed.org/ejurnal/index.php/medicina/article/view/292

Penelitian, B., \& Pengembangan, D. A. N. (2010). Riset Kesehatan dasar.

Sulaiman. (2016). Jurnal Ilmiah Research Sains VoL.2 No.1 Januari 2016, 2(1).

Sulaiman, \& Anggriani. (2018). Efek Postur Tubuh Terhadap Keseimbangan Lanjut Usia Di Desa Suka Raya Kecamatan Pancur Batu, 3(2), 127.

Sulaiman, Sutandra, L., \& Vera, Y. (2018). Pendampingan Kader Posyandu Lansia di Suka Raya. JDC, 2(2), 116. 